\title{
State Grid Corporation based on big data platform for Overstaffing \& Understaffing online analysis and Staff Allocation \& Forecasting Research and Practice
}

\author{
Jian Zhang ${ }^{1, a}$, Chengzhang Wang ${ }^{2, b}$, Jianbo He ${ }^{3, c}$, Wentao Liu ${ }^{4, d}$, Han Shen ${ }^{5, e}$ \\ ${ }^{1}$ Room 2-402, Building B of Times Group, 28 Shangdi West Road, Haidian District, Beijing, China \\ azhangjianhello@126.com
}

Keywords: Human Resource, Overstaffing \& Understaffing, Staff Allocation, Big Data.

\begin{abstract}
According to the principle of "uniform standard, uniform process, uniform platform, uniform configuration”, abide by the State Grid Corporation SG-ERP technical architecture, the big data technology is applied to the area of State Grid corporation human resources management Overstaffing \& Understaffing analysis, staff allocation and forecasting, which enhance the value of business data, strengthens the human resources management information system support capabilities for the business, lay the foundation for popularization and widely used in big data application of human resources.
\end{abstract}

\section{Introduction}

Since the "12th Five-year plan", the State Grid Corporation aims to build "One Strong Three Excellent (Strong grid, Excellent asset, Excellent service, Excellent performance)" modern corporation, clarify "maintain the momentum of development, maintain sufficient human resource, using advanced management method, to become first-class corporation." as guideline, and constantly deepen Four Management ideas (operate collectively, development intensively, lean management, standardization construction) and promote the Two Changes (change the way of grid development, change the corporation's development). After two major projects construction: SG186 and SG-ERP, the State Grid has undergone Development Planning stage, Pilot and Promotion stage, Deepen Application stage, and the Five Major construction stages, the corporation's informatization work has achieved remarkable results, with more than 10 years of informatization construction, the State Grid has accumulated massive data which enable the corporation carry out management analysis, data mining and forecasting.

By end of 2015, the State Grid Corporation initially completed a unified Human Resources Management Information System of which as the core of the ERP human resource level 1 deployment and full service module level 1deployment system. The system functions cover all business areas of human resources, and so far the system is applied to all units of the corporation. The functional construction focus on human resources department management control needs of the State Grid Headquarter. In respects of practical business application support, the existing system function is also simultaneously improved at each levels of units. With the application of new technology, the improvement of the management system, and the change of the deployment mode, the human resource information system has been put forward higher requirements, especially in respect of efficient data analysis capabilities which on the basis of big data.

The arrival of big data period brings new impacts and changes to the Human Resources Management, not only helps to get rid of the past simple empiricism, but also improve the scientific and objectivity of Human Resources Management, so as to enhance the value of human resource itself ${ }^{[3]}$.The Human Resources Management Information System focus on its sub-systems' business data, with the intensive management idea as the guide, to further strengthen the longitudinal management of the business. Under the support of corporation's big data related application of new technology, the value of the business data is enhanced greatly, which further enhance Human Resources Management information system’s ability to support the business. 


\section{Overall structure}

\section{Business Architecture.}

After informatization construction of SG186, SG-ERP stage, and rely on the ERP and customized information systems, the Overstaffing \& Understaffing analysis system, and internal human resources management was developed by the human resources department, and after years of informatization construction and data accumulation, the basic database was initially formed which enable the human resources department to do statistical analysis and making predictions. In order for better service on Overstaffing \& Understaffing analysis, as well as staff allocation for each units, departments, and positions of the State Grid, therefore to build an analysis and forecasting management model based on big data platform is needed. The model's business content includes graduates recruitment analysis and forecasting, overstaffing \& understaffing statistical analysis and forecasting, staffing statistics and analysis, etc. The model's business structure is shown in Figure 1.

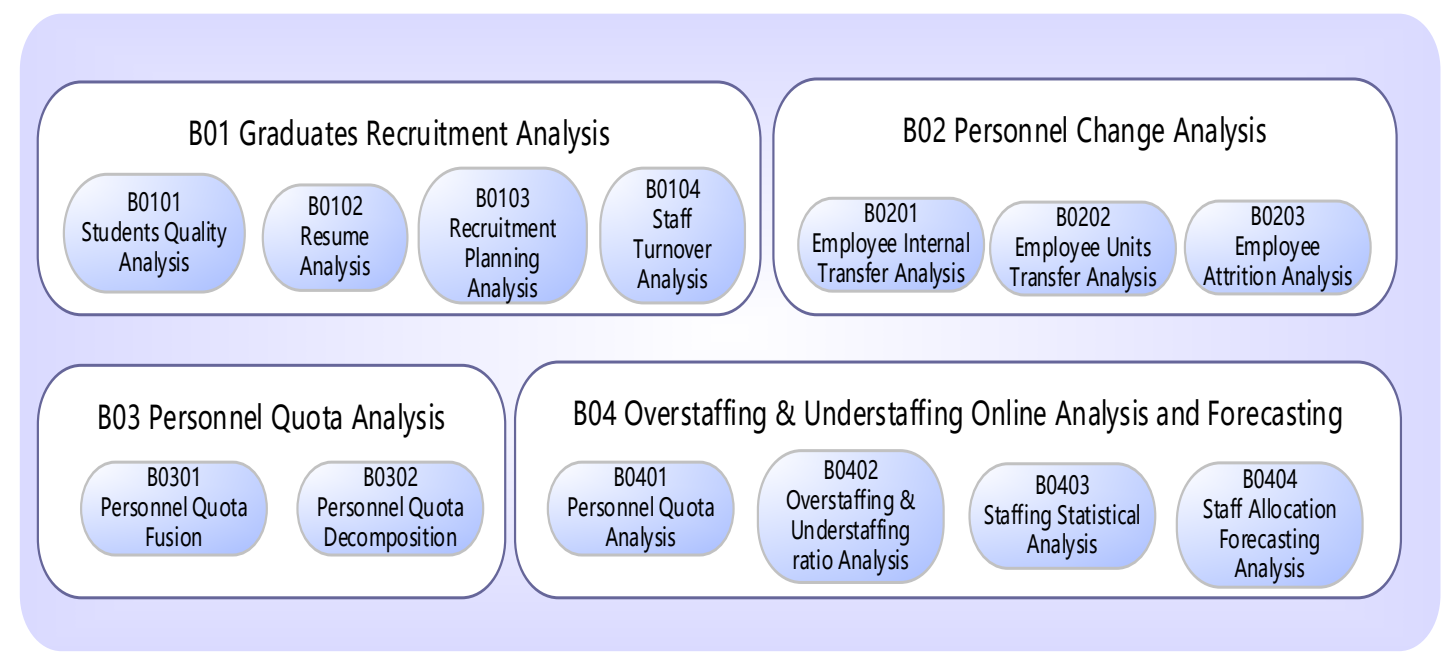

Figure 1: The business architecture of overstaffing \& understaffing online analysis and staff allocation \& forecasting based on the big data platform

\section{Application Architecture.}

Based on the big data platform for overstaffing \& understaffing online analysis and staffing allocation forecasting functions, and based on the development effort of human resources management information system, combined with the State Grid human resources business needs, the system has a total of 12 sub-applications, including the graduates recruitment program, the total number of candidates, graduates examination record, graduates admission situation, graduates turnover rate, students quality, personnel quota analysis, staffing allocation analysis, overstaffing \& understaffing ratio analysis, staffing allocation comparison, staffing trend prediction, etc. The application architecture is shown in Figure 2. 


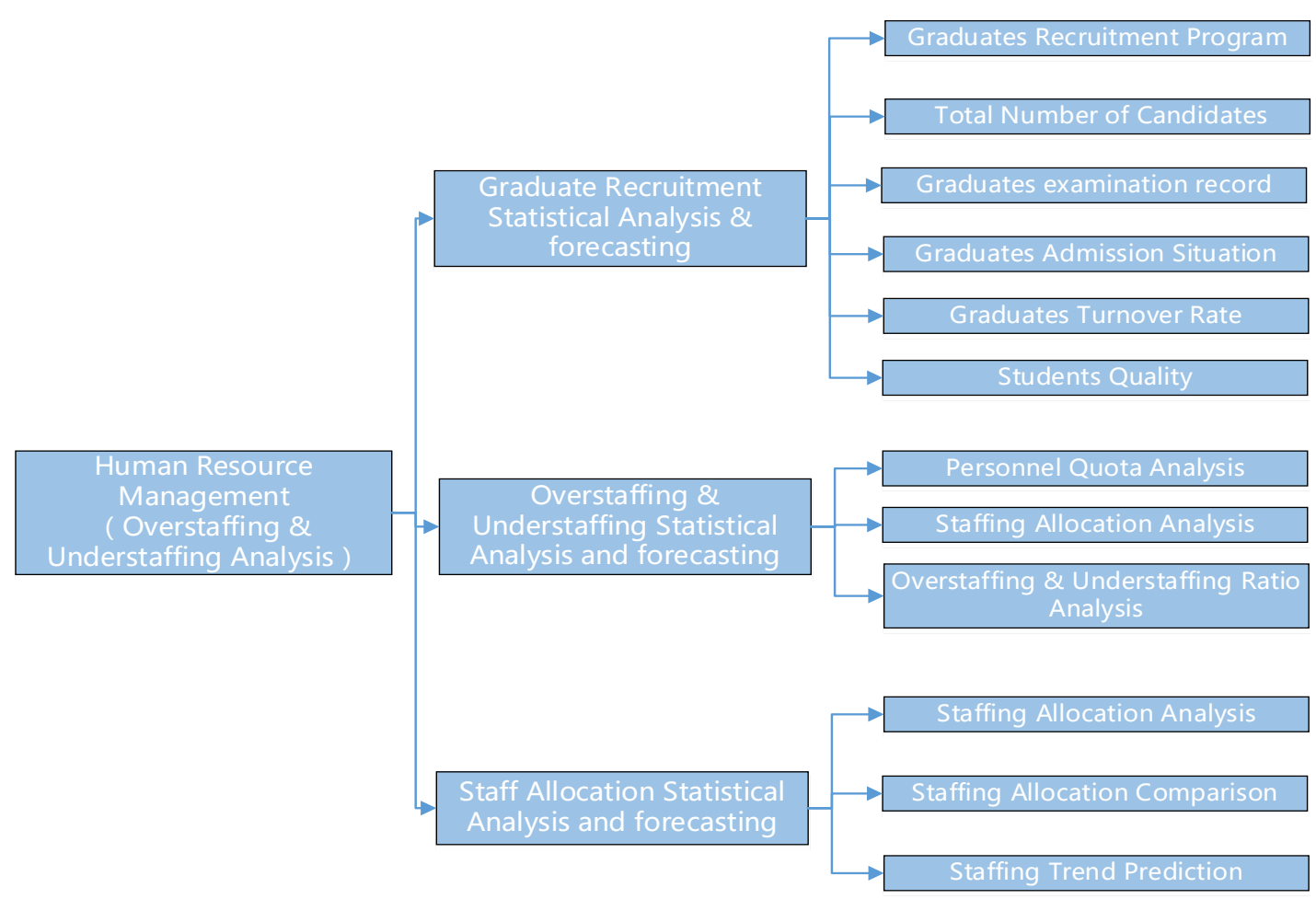

Figure 2: The Application Architecture of overstaffing \& understaffing online analysis and staff allocation \& forecasting based on the big data platform

\section{Data Architecture.}

Based on the big data platform for overstaffing \& understaffing online analysis and staffing forecasting, the data entity includes graduates recruitment program, graduates candidates, graduate examination record, graduate admission situation, Overstaffing \& Understaffing allocation, staffing allocation, etc. The data architecture is shown in Figure 3.

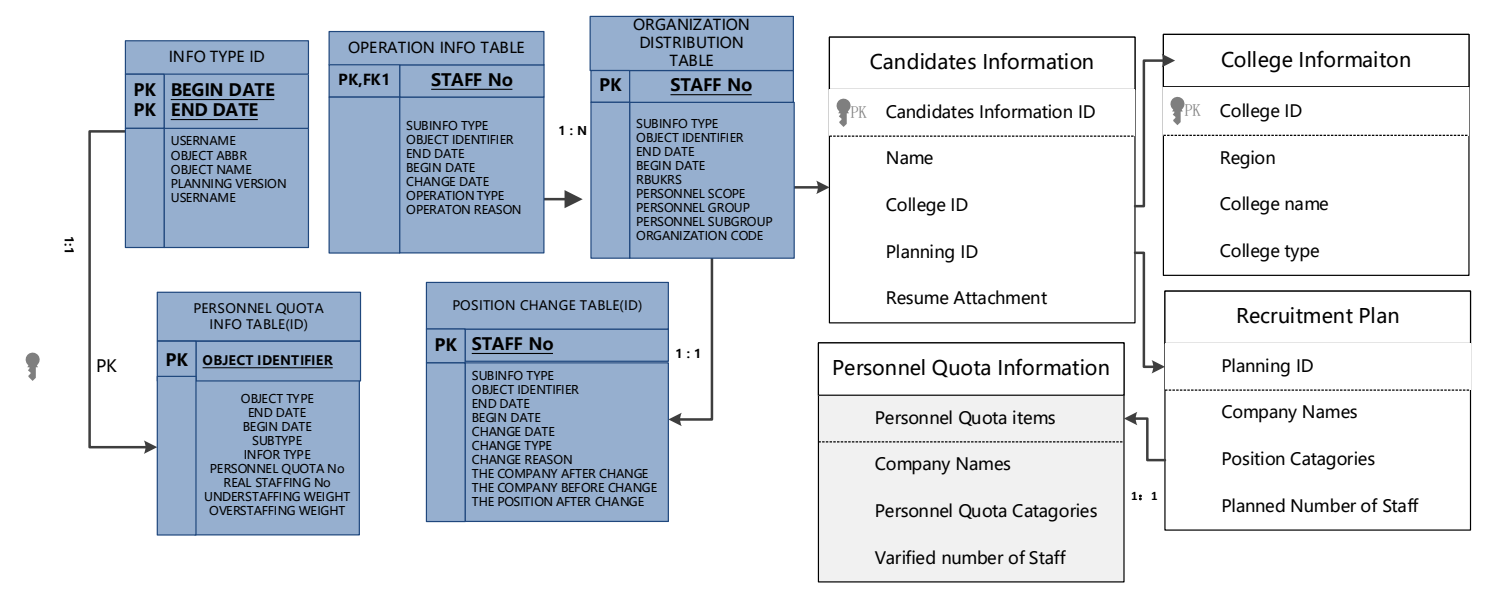

Figure 3: The Data Architecture of overstaffing \& understaffing online analysis and staff allocation $\&$ forecasting based on the big data platform

\section{Technical architecture.}

Based on the big data platform for overstaffing \& understaffing online analysis and staff allocation \& forecasting, the interface using tableau as business intelligence exhibit components, integrated with html, jsp, etc, and using oracle database as the application database, using the big data platform and Sybase IQ as business analysis data processing. The technical architecture diagram is shown in Figure 4: 


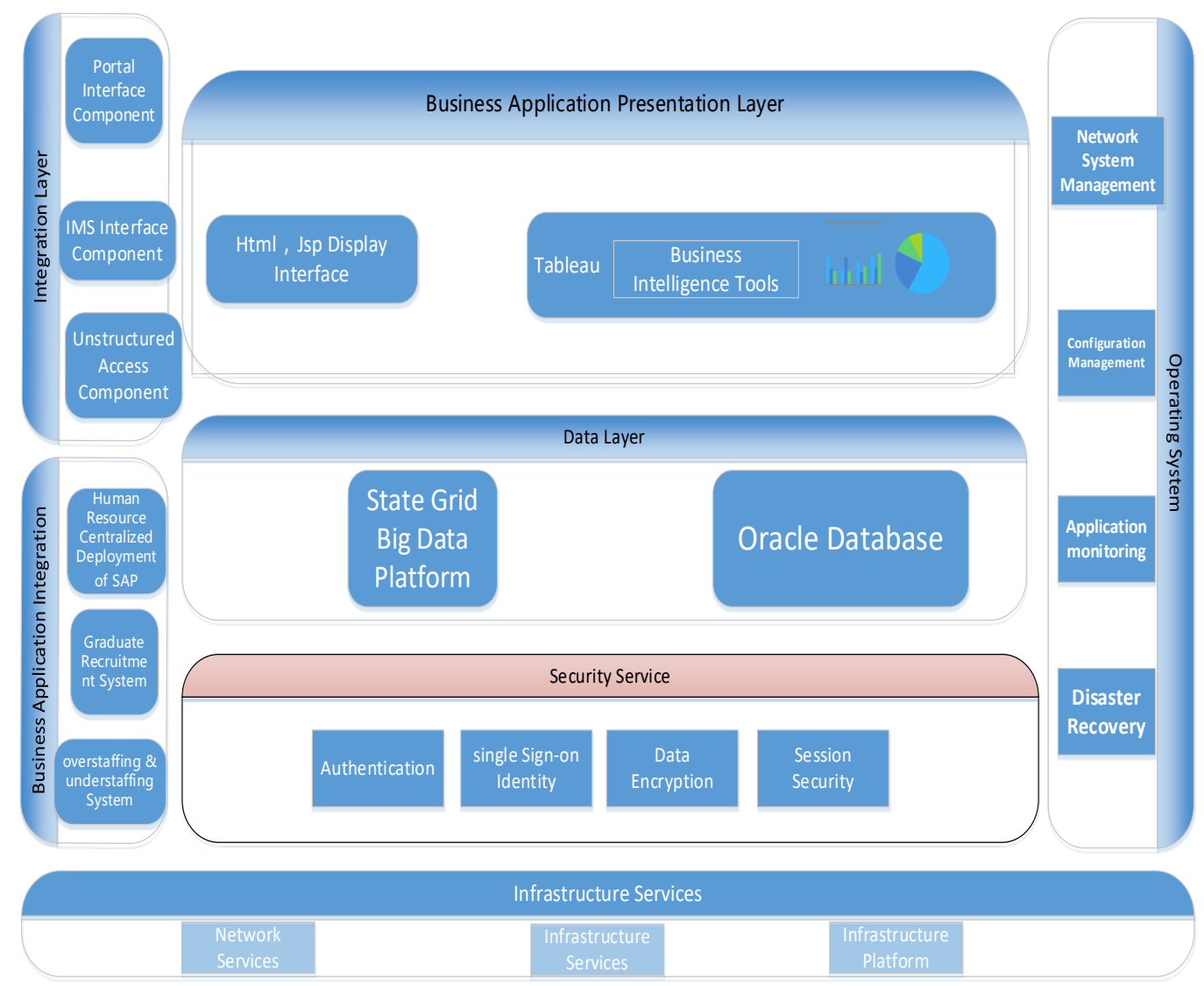

Figure 4: The Technical Architecture of overstaffing \& understaffing online analysis and staff allocation \& forecasting based on the big data platform

\section{Deployment Architecture}

According to the present situation analysis of overstaffing \& understaffing online analysis based on big data platform and staff allocation \& forecasting of the State Grid Corporation, the system adopts the level 1 deployment model, the specific deployment structure diagram is shown in Figure 5:

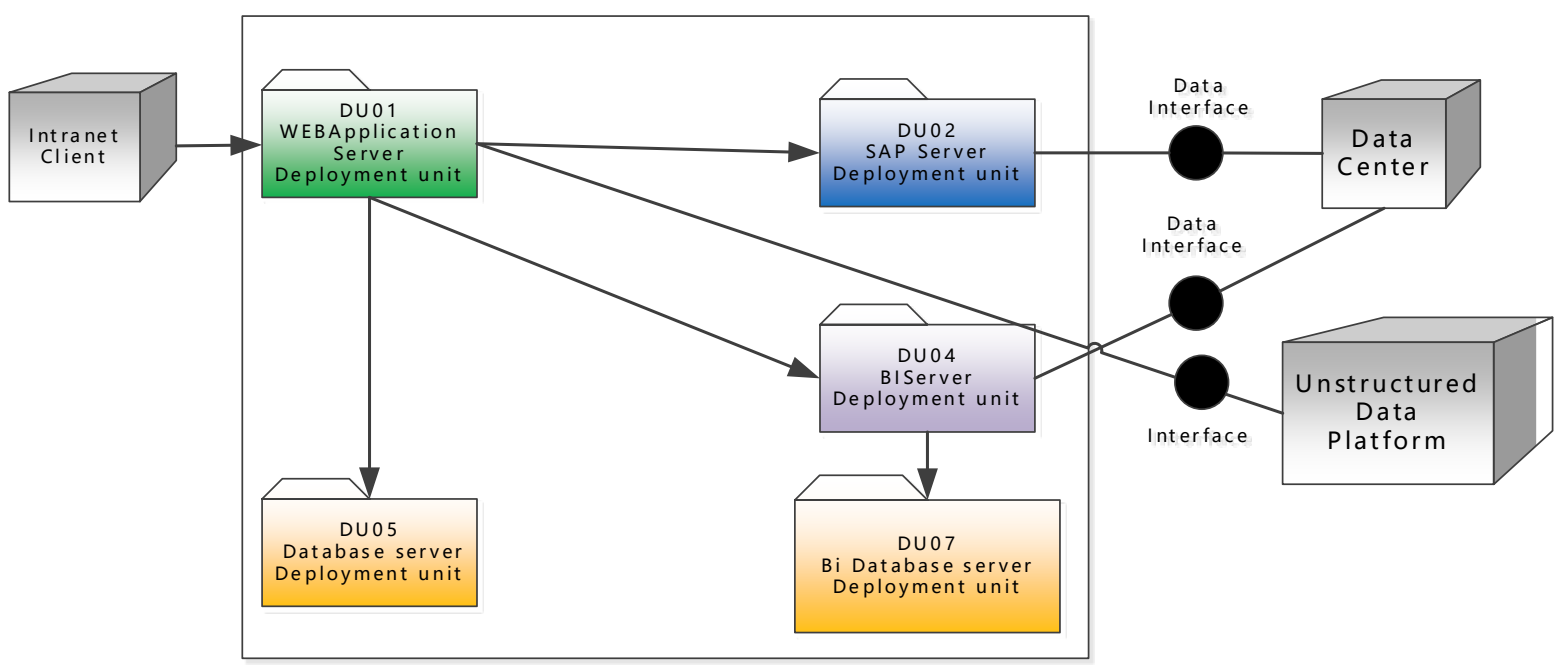

Figure 5: The Deployment Architecture diagram of overstaffing \& understaffing online analysis and staff allocation \& forecasting based on the big data platform 


\section{Application Integration}

Based on the big data platform for overstaffing \& understaffing online analysis and staff allocation \& forecasting, integrated with centralized deployment of SAP, Graduate Recruitment System, Overstaffing \& Understaffing system, IMS, and unstructured platform for data integration, and integrate interface with the Portal System, the specific deployment design diagram is shown in Figure 6:

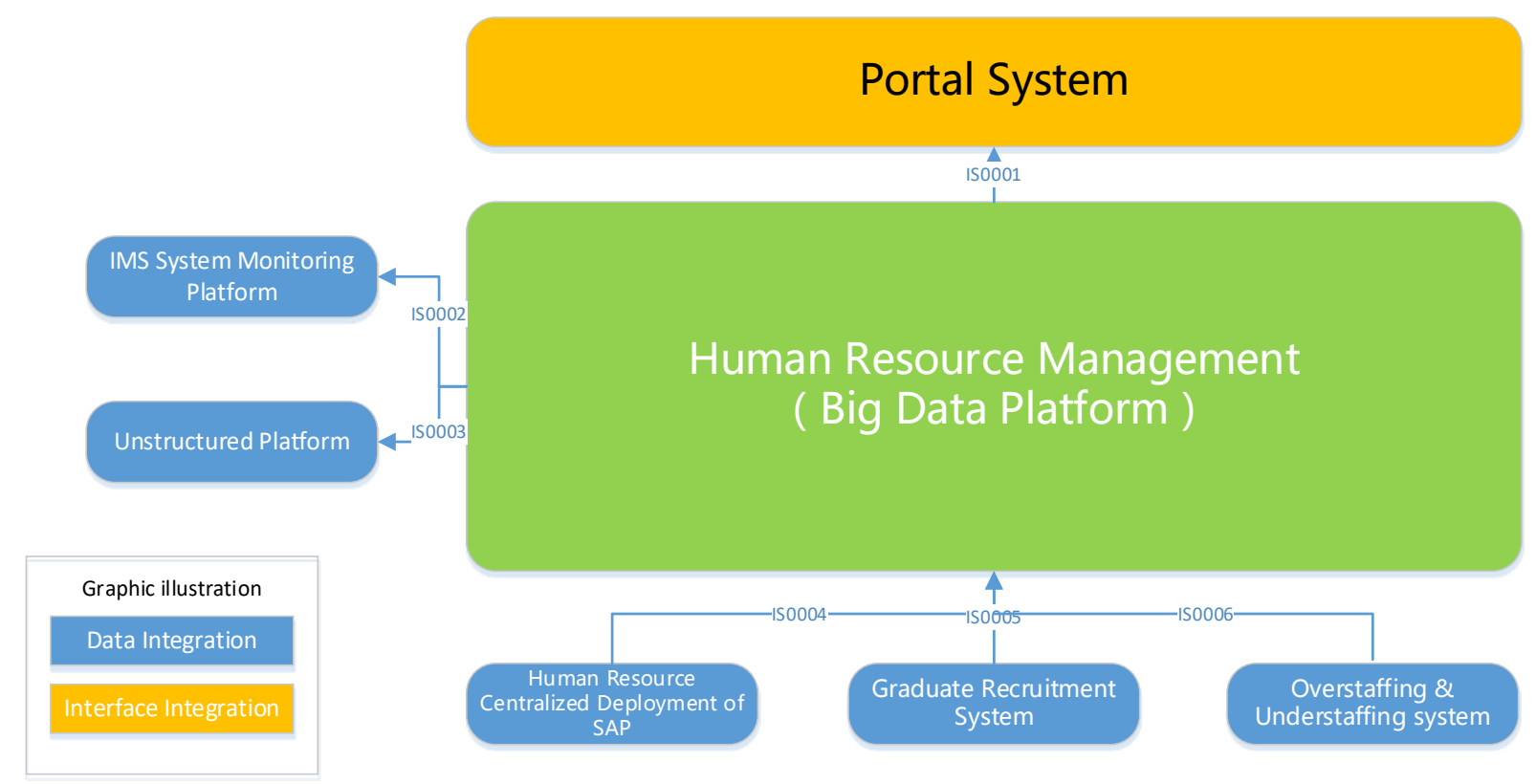

Figure 6: The Application Integration diagram of overstaffing \& understaffing online analysis and staffing allocation \& forecasting based on the big data platform

\section{Conclusion}

State Grid Corporation has huge amount of human resources business data, the company has more than 1.5 million employees of the data in the human resource information system for manage, it covers all the basic business data, which including Staff Management, Organization Management, Salary Management, Education Training Management, Human Resources Market, Recruitment management, E-University, etc. Human resources information system has been built for many years, the business covering vastly, the business data is highly regulated, the human resource management information system taking the lead to achieve the implementation of all the business module level 1 deployment, the business data is highly integrated, data acquisition is easier, which enable the system has the basic conditions for big data analysis and other new technology research and pilot constructions.

The big data era put forward new requirements for the human resource management, but it also brought a series of problems and challenges ${ }^{[4]}$. Big data storage, data transmission, and data analysis are emerging technologies, in recent years, to support big data research and practice is also vigorously advocated at the national level, the informatization of the state grid, especially for human resources informatization construction, large data application technology is still in the exploration stage, we must put effort on professional Research and Development strength, to make specific structural adjustment to the human resources information system, further optimize the data quality and data standardization, explore feasible and effective technical solution for the human resources big data analysis, lay the foundation for popularization and widely used in big data application of human resources. 


\section{References}

[1] Beijing China-Power Information Technology Co., Ltd. State Grid Corporation based on the big data platform for Overstaffing \& Understaffing online analysis and staff Allocation \& Prediction Research and Practice.2016

[2] State Grid Corporation. State Grid Corporation of Informatization Architecture Management Approach .2010

[3] Xueqing Liang. Application of big data in Human Resource Management. Administration Informatization of China, 2015, 18 (24): 77-77.

[4] Xinrui Zhang, Zhengfang Fan, Xiaobo Tao, The Application Space and Challenges of Big Data in Human Resources Management- based on Google and Tencent comparative analysis, Human Resources Development in China, 2015, 22: 52-57.

[5] Yin Zhang, Min Chen, Xiaofeo Liao, The application of Large Data present situation and prospect. Computer Research \& Development, 2013,S2. 